\title{
A STUDY OF INEFFECTIVE INVESTMENT TRUST AND PRECIOUS METAL MINING ISSUES
}

\author{
Edward G. Cale*
}

This article is the result of a six months' study of public documents relating to ineffective registration statements ${ }^{1}$ under the Securities Act of 1933. The paucity of statistical information in this field has meant that the chief means of arriving at conclusions has been through the laborious process of analyzing the registration statements individually. This procedure is so tedious and the material in the ineffective statements of such a nature, and so incomplete at times, that it is impossible to submit entirely satisfactory proof of all the contentions stated herein. A great amount of work on both effective and ineffective issues remains to be done before the results of the operation of the Securities Act may be properly evaluated. The following may, therefore, be considered a preliminary study in which certain subjects are shown to be worthy of further investigation and in which tentative conclusions are drawn from the information now at hand.

On June 30 , 1936 filings had been made under the Securities Act for approximately three years. At that time there were about $\$ 6,404,500,000$ worth of fully effective new issues ${ }^{2}$ registered with the Securities and Exchange Commission. New issues ineffective as a result of stop orders, refusal orders, and withdrawal orders amounted to $\$ 408,802,836$. Besides these classes there were $\$ 621,265,276$ worth of new issues under examination by the Commission; $\$ 7,170,000$, under notice of hear-

- B.A., 1928, University of Richmond; M.A., 1932, Ph.D., 1935, University of Virginia; VirginiaBrookings Institution Co-operative Fellowship in Economics, 1935-1936. Assistant Professor of Economics, Tulane University.

${ }^{1}$ Throughout this paper the term ineffective registration statements or ineffectives will be used as meaning statements under stop order, refusal order, or withdrawal order. In the case of withdrawal orders the registrant first asks permission to withdraw the statement and the Commission then issues an orier consenting to withdrawal, if such action is considered in accord with public interest. The fact that the registrant's request for withdrawal precedes the Commission's order consenting thereto is to be borne in mind whenever the expression withdrawal order is used in this paper. Morcover, it should be recalled that on April 6, 1936, in Ex parte Jones, 298 U. S. I, the Supreme Court held that the Commission could not forbid the withdrawal of a registration statement, cven after stop order proceedings had been initiated.

2 The Technical Division of the Securities and Exchange Commission regularly publishes information regarding new issues. By the term, "new issues," is meant securities which are neither issued in reorganization in exchange for other securities nor as a result of a voting trust agreement where an issue is sold to the public representing other securities deposited with voting trustees. This paper is concerned only with new issues in this sense. 
ing; $\$ 914,103$, effective under notice of hearing; and $\$ 10,039,225$ effective under notice of deficiencies. ${ }^{3}$

Doliar Amounts Represented by Registration Statements for Ineffective and
Effective Issues Under the Securities Act (As of June 30, 1936)

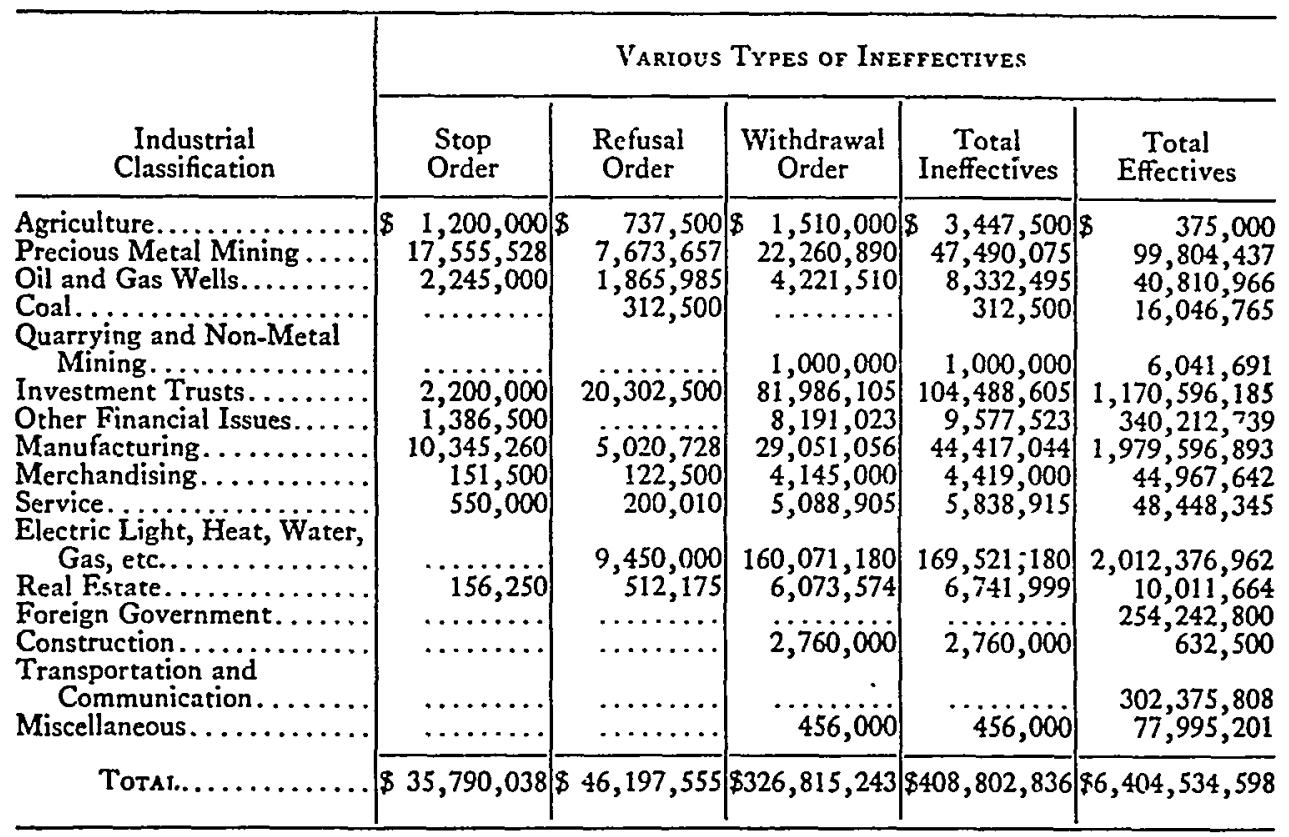

The last three classes of securities are so small in amount that they can be dismissed as inconsequential. This cannet be done with the issues under examination, however, because such issues were larger in amount than the sum of all ineffective statements combined. The group under examination was so large that what has happened to the statements in it so far and what may yet happen to them may modify the conclusions of this paper as to the proportion of ineffective to effective statements. If a larger proportion of them become ineffective than is represented by the comparison of ineffective and effective statements as of June 30,1936 then the Act has been more restrictive than this study indicates; if a smaller proportion becomes ineffective, then the Act has been less restrictive than the study indicates. It is probable that the Act should be considered slightly more restrictive than the study indicates because within the group of statements under examination are a few which have been there for some time and which may for that reason be considered as having less chance of becoming effective than the average registration statement. The following summary gives the status of the registration statements under examination on June 30,1936 as of October 24,1936 :

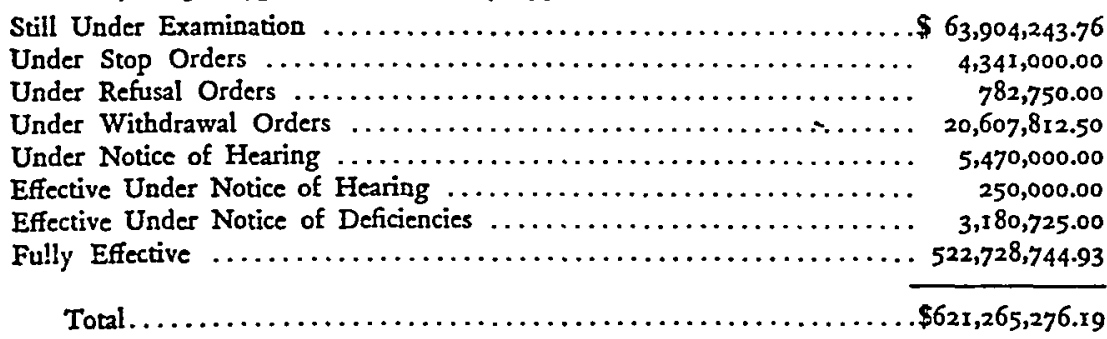

4The figures given in this table are subject to a large amount of error for two reasons. First, the registrant is required to esimate the gross proceeds of the issue at the time the statement is filed and to pay his registration fee on the basis of this estimate. If the actual offering prire to the public is 
It is proposed herein ( $\mathrm{I}$ ) to present certain material of a more or less statistical character concerning ineffective issues, especially investment trust and precious metal mining issues and (2) to indicate some of the reasons why they became ineffective.

At the outset, it is interesting to consider the way in which the Securities Act has affected issues of various types. This can be done by comparing the dollar amounts of ineffective issues in the different classes of securities with the dollar amounts of effective issues. The preceding table gives this comparison, breaking down the amounts of ineffectives on the basis of the Commission's order which made them ineffective.

This table shows that with the exception of the public utility group the two largest classes of ineffectives are found in the investment trust and precious metal mining. groups. The ineffectives in the utilities group consist mainly of a few comparatively large issues which have been withdrawn by the registrants for technical reasons, a good illustration of this being the withdrawal of a registration statement involving $\$ 48,750,000$ because of the objection of a supervising public utility commission.

The manufacturing group also has a large volume of ineffectives. This, however, is to be expected because of the great number of companies which fall within the manufacturing classification. It includes the processing of everything from transportation equipment to alcoholic beverages. The number of alcoholic beverage ineffectives was especially large, including $\$ 23,362,368$ of ineffective issues and leaving only $\$ 21,054,696$ of ineffectives in all other types of manufacturing. The reason for the large number of registration statements for alcoholic beverage issues lies, of course, in the repeal of the 18 th Amendment.

One reason for treating the investment trust and precious metal mining issues together herein has been intimated, i.e., excluding the public utility group they represent the two largest groups of ineffective issues. A second reason is that both types of issues have been misused by promoters to such an extent as to bring them into bad repute. This has long been true with precious metal mining issues. The investment trust issues have been sold in this country on a large scale only during the past ten or twelve years and have encountered severe criticism chiefly since 1929.

Though the precious metals group and the investment trust group both have a large volume of ineffectives, it is apparent from the table that the Securities Act

different from the one expected, the gross proceeds from the issue are different from the amount estimated. In the case of those statements which never become effective there is never any offering price and the figures necessarily depended upon are those estimated by the registrants. For effective issues, reports of the Technical Division of the Securities and Exchange Commission have been relied upon. These are based as far as possible on the actual offering price. The result is that the two sets of figures are not always strictly comparable. The second possibility of error arises from the fact that the present classification of issues according to industry is not exactly the same as the one used when the Securtities Act was administered by the Federal Trade Commission. The Technical Division has not yet had the tine to go back and reclassify the effective issues according to present standards. The writer has been compelled to classify the ineffective issues because the Commission publishes no analysis of them. In making this classification the classification now used by the Commission has been followed as closely as possible. The result is that the industrial groupings used are not always strictly comparable throughout the table. 
has operated so as to keep a much larger proportion of the former than of the latter from being offered for sale. The sum of effective and ineffective investment trusts issues is $\$ 1,275,083,790$ and the sum of effective and ineffective precious metal mining issues is $\$ 147,294,512$. The amount of ineffective investment trust issues- $\$ 104$,488,605 -and the amount of ineffective precious metal mining issues- $\$ 47,490,075-$ constitute $8.19 \%$ and $32.24 \%$ of the sum of effective and ineffective issues in each of the two classes. Thus the proportion of ineffectives to effectives in the case of precious metal mining is almost four times as large as it is in the case of investment trust issues. The following table contains a comparison of this type for all groups of issues which on June 30,1936 contained as many as $\$ 40,000,000$ of effective and ineffective issues combined:

Type of Issue by Industry

Precious Metal Mining

Oil and Gas Wells

Merchandising

Electric Light, Heat, Water, Power and Gas Companies. .

Investment Trusts $\ldots \ldots \ldots \ldots \ldots \ldots \ldots \ldots \ldots \ldots$

Financial Companies Other than Investment Trusts......

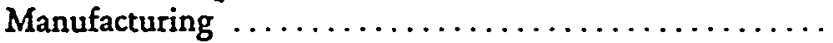

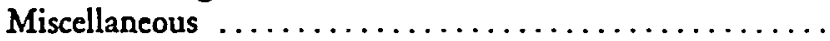

Transportation and Communication $\ldots \ldots \ldots \ldots \ldots \ldots$

Foreign Governments
Ineffectives as a Percentage of Ineffectives and Effectives Combined

32.24

16.95

8.96

8.42

8.19

2.74

2.12

$.5^{8}$

.00

.00

This table reveals that the Securities Act has borne heaviest on the traditionally speculative precious metal mining and oil well issues. It also shows that the investment trust issues have fared rather well, since it is now possible for the registrants to offer for sale $91.81 \%$ of all securities for which there are either ineffective or fully effective registration statements.

Just here it is well to state that the percentages given in the table above tend to indicate that the Act is more restrictive than it actually is. This is due to the numerous exemptions from registration under the Act, and to the withdrawal of many statements when it was learned that registration was unnecessary. It is impossible for anyone not employed by the Commission to know the number of withdrawals which have taken place in this manner, because material for such a study is not made available to the public. There is, however, enough evidence available to lead to the conclusion that the possibility of withdrawing registration statements under exemptions has had considerable influence in allowing registrants to offer their securities for sale.

The information available on this subject is derived from two sources. First, the request for withdrawal of the registration statement is sometimes made a part

\footnotetext{
- Ineffectives are expressed here as a percentage of effectives and ineffectives combined instead of as a pereentage of all filings because the proper classification of statements under examination on June 30,1936 has not yet been definitely determined. Sec note 3 , supra.
} 
of the material filed for public inspection. ${ }^{8}$ In some instances where this happens the reason for desiring withdrawal is given. Secondly, one class of exemptions is provided for in the Commission's Release No. $182 .{ }^{7}$ This applies to relatively small offerings. Under this release the registrant claiming exemption for offerings between $\$ 30,000$ and $\$ 100,000$ is required to file a prospectus with the Commission but does not have to file a registration statement. When it is found that a registrant has withdrawn a statement and later filed a prospectus required by Release No. 182 , it may be assumed that withdrawal was granted because the exemption was claimed.

When a registration statement is placed under refusal or stop order, it may generally be assumed that the securities are no longer offered for sale, though this is not always true because a few such registrants have filed prospectuses under Release. No. 182 showing that they intended to sell securities under the exemptions provided therein. ${ }^{8}$ Since stop orders and refusal orders combined accounted for but $\$ 8 \mathrm{x}, 987,593$ of ineffectives out of a total of $\$ 408,802,836$, it is important to remember that withdrawal of a statement in many cases does not mean that the issue will not be sold. This may be illustrated by a study of the reasons why investment trust issues were withdrawn in which the only sources of information were the two described in the preceding paragraph.

On November $12,1935^{\circ}$ there were forty-one ineffective registration statements for investment trust issues under the Securities Act, amounting to $\$ 31,225,213.75$. Of this sum, one statement covering an offering of $\$ 500,000$ was ineffective because of a refusal order and six statements were ineffective because of stop orders. The aggregate involved in the stop order cases was $\$ 6,700,000$. The thirty-four remaining statements were covered by withdrawal orders, the aggregate amount involved being $\$ 24,025,213.75$. Of these thirty-four statements there were fifteen cases in which the request for withdrawal was not to be found in the public files, seven others where no reason for requesting withdrawal was given though the request was filed, six cases in which the request for withdrawal indicated that the registrant did not at that time intend to claim exemption, five cases in which some form of exemption was claimed, and one case in which a prospectus was later filed under Release No. 182. The total amount involved in the few cases where it was clear that withdrawal had been granted because of exemptions was $\$ 13,329,623.75$, this figure being more than half the aggregate of all new investment trust issues under withdrawal order at that time. This fact should not be taken as indicating that half of all statements withdrawn can now be sold as exempted securities. My study of the investment trust group showed that such was the case with that group at the time the study

- All requests for withdrawal have recently been made a part of the public files.

'Sinee this study was made Release No. 182 has been repealed and replaced by Rules 200-209. The exemption of offerings between $\$ 30,000$ and $\$ 100,000$ has been rescinded in certain cases by Rules $20 \mathrm{x}$, $204,205,206$ and 208.

${ }^{8}$ The imposition of a stop order or refusal order does not mean that the securities covered by the registration statements involved will never be offered for sale, because the Commission is at liberty to lift these orders whenever the registrant amends its statement in a manner satisfactory to the Commission.

- This date is of no special significance, being simply the time the study referred to was begun. 
was made. It is probably not true now, because the amount of securities withdrawn under exemptions was at that time inflated by the inclusion of one relatively large issue involving more than $\$ 9,000,000$, and this proportion of large issues in the class of withdrawals due to exemptions has perhaps not been maintained. Exemptions are open to certain registrants in practically all industrial groups, however, and to the extent that they have been the basis for withdrawal of registration statements the Securities Act has been less restrictive than a simple comparison of ineffective with effective issues would indicate.

It is very difficult to get any statistical basis for comparing the investment status of effective and non-effective issues because little study has yet been made in that direction. The Securities and Exchange Commission has not published such a comparison, because it is concerned rather with obtaining a full and fair disclosure than with the fundamental soundness of the issues. Thorough analysis of all statements filed under the Securities Act even in one large industrial group is a task beyond a single individual's accomplishment because of the rapidity with which such registration statements increase in number. The following discussion of factors affecting the investment status of ineffective investment trust and precious metal mining issues is intended merely to indicate some of the things which would have to be taken into consideration in such a study. It would also be necessary before determining the extent to which ineffective issues would have been less desirable from an investor's viewpoint than effective issues to make similar studies of the effective issues in order that comparisons might be made.

A study of forty-one ineffective investment trust issues led to the conclusion that they all offered very poor risks, being open to attack on one or more of the following grounds:

r. In three cases purchasing the certificates would have meant buying into a double load, i.e., buying certificates in one trust which intended to invest all or a large part of its funds in the certificates of other trusts. Because the managers of the trust make a profit in each transaction, the investor would be better off if he himself bought certificates in the second trust directly.

2. The certificate holders in many instances would have been forced to share profits with the managers of the trust who assumed no risk. This was because the managers were to receive, in addition to the regular fees received by them from the certificate holders, half of the profits of the trust after the certificate holders had received their original investment plus something like a $5 \%$ or $6 \%$ return thereon.

3. Practically all the trusts were sponsored by persons whose interests conflicted with the interests of the certificate holders, i.e., the managers stood to benefit by such practices as selling securities to the trust, thus making a profit in addition to their regular fee for management. This criticism applies to the so-called fixed trusts as well as to the management trusts, because the trust indenture in many of the former provided loopholes regarding the substitution of securities in the trust, etc., which enabled the managers to buy issues other than those on the "approved list." 
4. Many of the trusts were sponsored by those whose records indicated that investors purchasing into the trust did so at great risk. These records indicated moral weaknesses, such as having been proved dishonest, as well as records of financial failure. A good example of the first type of weakness is a promoter who resorted to forgery to present a more enticing prospectus to potential investors.

An example of an issue involving a poor type of risk because of the financial record of its management was that of a small company which had been in existence for only a little over three years. It had sold $\$ 90,000$ in common stock. When it applied for registration with the Commission for an additional stock issue its total assets of $\$ 7,309.07$ consisted largely of securities pledged as collateral for a $\$ 3,000$ bank note. The company had never paid dividends. It showed a net loss of $\$ 56,350.68$ in $193 \mathrm{I}$, of $\$ 20,110.20$ in 1932 , and of $\$ 6 \mathrm{I}_{\text {. } 4 \mathrm{I}}$ in 1933 . For the period October 3r, 1933 to April 30, 1934 it had a net income of \$1.40.

One comparison between the investment status of effective and non-effective investment trust issues can be made with reasonable assurance of accuracy. This pertains to selling commissions. Declarations in the ineffective registration statements examined revealed that selling commissions would have averaged more than $10 \%$ of the offering price to the public. Selling commissions on effective issues covering the same period according to the Commission's figures would have been less than $8 \%$ of the offering price. This comparison shows, other things being equal, that the public would have gotten less for its money in the case of ineffective issues than it actually received in the case of effective ones.

A study of II6 precious metal mining issues disclosed some interesting facts concerning such issues, though here again it was impossible to make an adequate comparison with effective issues.

One of the best indications of the quality of the ineffective precious metal issues lies in the manner of their promotion. So many of the promotional features of such issues are identical for different companies that it is possible to illustrate what happens in almost every case by reference to a typical issue, a proposed offering by the Unity Gold Corporation described in the "Decisions" of' the Securities and Exchange Commission.

J. L. King acquired the Katinka Group of mining claims in Cripple Creek, Colorado, on July 15 , I 931 under a royalty lease for three years. He also acquired an option to purchase the property before the expiration of the lease for $\$ 15,000$, royalties to apply on the purchase price. The consideration for the purchase option was one dollar and the acceptance and performance of the lease. Having thus acquired the use and control of the claims at no expense other than the usual obligations to operate the property and to pay royalties on the returns, King organized the Industrial Gold Mining Company and assigned to it the lease and option in consideration of the issuance to him of 2,000 shares of stock having a par value of $\$ 1.00$ per share. 
The company expended about $\$ 5,560$ in developing the property, but produced no gold and hence paid no royalties. As a result of the need for additional capital the lease and option were assigned to the Unity Gold Corporation. The prospectus proposed to be used by the latter corporation states that it paid to the Industrial Gold Mining Company $\$ 5,000$ and 599,995 shares of its fully paid capital stock with a par value of $\$ 1.00$ per share for the lease and option. In this transaction it was stipulated that the Industrial Gold Mining Company would immediately donate and deliver to the treasury of the Unity Gold Corporation 475,000 shares of the total shares received by the Industrial Gold Mining Company; that the balance of the shares (124,995) to be received by the Industrial Gold Mining Company were to be issued in the names of various persons, and among those so named was Robert L. Maxwell in whose name rog,435 shares were issued. The prospectus further states that Maxwell and others of the management donated to the corporation 50,000 shares of their stock in May 1933 for the purpose of liquidating all indebtedness incurred by their management.

The registration statement filed by the Unity Gold Corporation stated that the number of shares authorized by the articles of incorporation was 600,000 with a par value of $\$ 1.00$ per share and that there were outstanding 168,058 shares. Robert L. Maxwell was said to own $36.7 \%$ of the outstanding shares amounting to 61,677 shares, or more than $10 \%$ of the total amount of stock authorized. The registration statement carried a balance sheet as required by the Commission. The total assets shown by this balance sheet amounted to $\$ 620,090.72$ as follows:

Property, plant and equipment $\ldots \ldots \ldots \ldots \ldots \ldots \ldots \ldots \ldots \ldots \ldots \ldots \ldots \ldots \ldots$

Less reserve for depreciation and depletion.............. 268.31

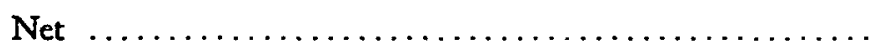

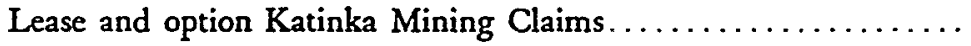

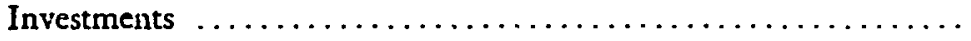

$\$ 4,669.35$

$605,047.00$ 60.00 298.29

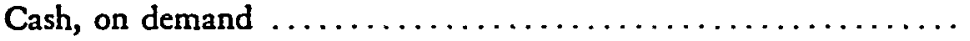

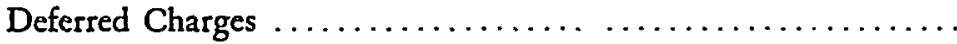

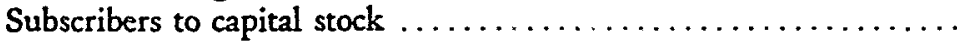

$8,524.79$

$1,447.37$ 43.92

Registration was sought for 419,212 shares to be issued to the public. After a hearing by an examiner of the Commission, the registration statement was placed under stop order because certain features concerning the promotion were not properly described.

The assets of the company were in a very large measure the result of mere bookkeeping entries. There was absolutly no-reason for believing that the lease and option on the Katinka gold mining claims was worth $\$ 605,047$. When it is remembered that the lease and option cost J. L. King just one dollar in the first instance, and that the property could have been actually purchased for $\$ 15,000$, the amount entered as the value of the lease and option is seen to mean practically 
nothing. Neither King nor Maxwell purchased the property, the lease and option were merely assigned to the company. The Unity Gold Corporation did not own the property at the time the registration statement was filed. In fact, \$14,956.08 of the net proceeds of the issue to the public were to be used for making a final payment for the property.

This feature of fictitious assets is general among the ineffective registration statements covering gold issues. In most cases, however, answers in the registration statements are so incompletely given that it is impossible to tell just what the promoters have expended for the stock which they received. Wherever the amount is given, it is almost always very small. It is also significant to notice that the company carried on its statement a surplus amounting to $\$ 454, \mathrm{rr} 2.55$ as of September 30 , r933. This was the result of issuing capital stock of a corporation in payment for claims valued at the equivalent of the par value of the stock and then having a portion of the stock donated to the treasury of the corporation. To the average person this state of accounts may spell prosperity. To the person more familiar with the accounting procedure used by gold mining companies, another item representing a deficit in the Earned Surplus account in the amount of $\$ 10,566.80$ is of more significance, because it indicates that the company's operations were being carried on at a loss.

One thing about the above case is not typical and that is the amount of stock which goes to the promoter. Analysis of the ineffective statements covering gold issues indicates that the promoters would get more than $50 \%$ of all stock which is to be outstanding after the entire issue is sold. Inasmuch as it is always unlikely that a whole issue will be sold, it is apparent that the promoters would have received even a larger percentage of the outstanding stock had the issues been offered for sale.

Most gold mining companies with ineffective registration statements have no actual profit and loss statement, because they have not reached the point where pro duction of gold ore is sufficiently profitable to pay expenses. Expenses are usually charged to development, therefore, and are quite frequently entered on the balance sheet as an asset under the caption "Deferred Charges." In the present case they were charged to "Earned Surplus" in the Net Worth section of the balance sheet, a procedure which conforms better with the truth.

As an indication of the extent of development of issuers having the ineffective gold mining issues, it is significant that registrants submitted profit and loss statements in only 16 out of 116 cases, and that only 3 of the 16 submitting profit and loss statements showed a net income for the period immediately prior to the filing of the registration statement. From this showing it is apparent that $\mathrm{Ir}_{3}$ out of $1 \mathrm{x} 6$ of the proposed issues could not have appealed to anyone demanding proof of carning capacity before investing. The earnings in the remaining three cases, even if the accounting procedure employed be accepted as correct, were so small as to be inconsequential. 
Another indication of the quality of the issues covered by ineffective registration statements of gold mining companies is found in the expenses of distributing the issue to the public. This cost would have absorbed approximately one dollar out of every three that the public expended for its stock. In a substantial part of the cases the promoter of the issuer would have acted as underwriter or distributor of the issue and would have received the selling commissions.

It is interesting to summarize the preceding discussion by indicating in a general way just what the investor would have received for a dollar in the average case, if these precious metal mining issues had become effective. He would have purchased a certificate which in a portion of the cases might have rendered him liable to assessment for the company's debts. Out of his dollar, 33 cents would have gone to pay underwriting commissions and other selling expenses. Of the remaining 67 cents some would have been employed in developing the mining property, some for working capital, some perhaps to pay for property. Practically all the cash for development, working capital, and purchase of property would have been contributed by the public. The promoters would have received slightly more than a share of stock for each one bought by the public without, as a rule, paying cash for it.

Under the issuer's huge capitalization, the operations would have had to be unusually successful for the investor to receive dividends equal to $6 \%$ on his investment, for the promoter's income would also have to be earned. Furthermore, no return to the investor could have been considered income until his principal was returned because a gold mine is a wasting asset. This last consideration as well as some of the others are applicable to both ineffective and effective statements.

$\mathrm{U}_{\mathrm{p}}$ to this point this paper has been built around statistical material pertaining to ineffective investment trust and precious metal mining issues. Because it has been difficult in many cases to secure material subject to quantitative measurement it has been necessary at times to portray conditions by simply describing them as far as possible in the light of available information. Attention will now be turned to the second part of the study in which an attempt is made to show why investment trust and gold mining issues become ineffective.

Limitations of space prohibit detailed recounting of the information.required to be furnished before a registration statement may become effective. Suffice it to say that the theory behind the act is that every issue of new securities to be sold in interstate commerce should be accompanied by full publicity and information and that no essentially important element attending the issue should be concealed from the buying public. This requires the submission by each issuer of a very considerable amount of detailed information concerning its background, officers, promoters, financial affairs and financial condition. It is undoubtedly true that in many cases the preparation of a registration statement is an expensive and timeconsuming process. It is also probable that most of the questions asked in a regis- 
tration statement are superfluous in any particular case. It is equally true, however, that the investor's interest might be impaired in any particular case if any of the questions called for in the registration statement were omitted. It is a case of having to require all companies, both those which might deliberately try to rob the public and those which would not, to give answers to a sufficient number of questions to disclose those occasions where the investor's property is likely to be jeopardized.

The following illustrations from gold mining issues serve to indicate in a general way why statements become ineffective. The information was secured from transcripts of stop order hearings and shows the attitude of the Commission's staff.

Item number three in the A-r form used by the Commission in connection with new and untried projects requires a brief description of the character of business done or intended to be done. Study of the numerous cases in which the transcripts show that an objection was raised by the examiners to answers to this question indicate three major mistakes made by issuers. First, many simply copied in this space their charter provisions authorizing them to do practically anything. This, of course, does not show the investor exactly the type of business in which the company is engaged. Second, registrants frequently fail to include under this item important undertakings planned or already begun. The examiners sometimes get information outside the registration statements which leads them to suspect such omission, but it often appears in some other part of the registration statement. For instance, the financial statements of a gold mining company and a company devoted to experimenting in airplanes filing registration statements at about the same time showed inter-company interests not disclosed in answer to item three, thus proving that answers to that item in both statements were untrue. Thirdly, registrants often fail to state in answer to item three whether the business mentioned is business already done or business intended to be done. It is apparent, that this might be of material importance in that it could mark the difference between actuality and mere enthusiasm for the future.

The answer to item twenty-seven calls for a detailed statement of the specific purposes and the approximate amounts devoted to each purpose, so far as determinable, for which the net proceeds of the issue are to be used. This item assumes that the investor is entitled to know the uses to which his money is to be put. Registrants often fail to give these items in sufficient detail. In many cases pertaining to gold mining no attempt at all is made to break down the gross proceeds.

Item thirty-nine secks to disclose information regarding any amount paid to the promoter of the issuer during two years prior to registration, or intended to be paid to him. Quite often the promoters of gold and silver mining companies have received what appear to be handsome profits as the result of selling property to the registrant or by rendering professional services yet nothing is said in the registration statement concerning these gains. This, of course, constitutes an omission to state a material fact. 
The above are but a very few of the objections raised to answers to questions in the registration statements of precious metal mining companies. The list could be extended indefinitely, because no two statements are exactly alike and one statement may have as many as twenty-five or thirty deficiencies. The illustrations chosen are of omissions met in the general run of cases where fraud on the part of the issuer is perhaps not intended. It is undoubtedly true that many such errors arise from ignorance on the part of those filing the statements.

The conclusions to which this paper points may be summarized as follows: First, the dollar amount of ineffective issues under the Securities Act of 1933 is small relative to the dollar amount of effective issues. Second, the exemptions provided in the Act make it less restrictive than a simple comparison of effective with ineffective issues would indicate. Third, the Act has operated in such a way as to render ineffective a rather large percentage of precious metal mining issues, but investment trusts have been able to offer for sale most of the securities for which they have sought registration. Fourth, available information indicates that the ineffective investment trust and precious metal mining issues would have constituted poor risks for investors. Fifth, sufficient material for an adequate comparison of the investment status of effective and ineffective investment trust and precious metal mining issues has not yet been compiled. The one basis for comparison so far, i.e., selling commissions, indicates that the latter are inferior to the former. 